\title{
DE LA ASIMILACIÓN AL APARTHEID SOCIAL \\ Claves de un debate normativo inacabado sobre la integración de los inmigrantes en Francia
}

\author{
Kayamba Tshitshi Ndouba \\ Departamento de Derecho Constitucional \\ Universidad Nacional de Educación a Distancia
}

http://dx.doi.org/10.5209/rev_NOMA.2015.v45.n1.51330

\begin{abstract}
Resumen: Este articulo analiza la pertinencia de la brecha entre la doctrina de integración republicana y las dinámicas sociológicas, políticas, culturales y demográficas de las relaciones comunitarias "étnicas" que inducen a un estado de "multiculturalismo de hecho", un multiculturalismo a la francesa. Resultado no deseado de la normatividad hegemónica ciega e hipócrita del principio de unidad cívica de la nación, el multiculturalismo a la francesa, puede presentarse por lo menos teóricamente, como la confluencia de cinco subprocesos: la etnicización del espacio urbano y el debilitamiento del vinculo social (lien social), la especialización territorial y la relegación social, la "politique de la ville" como política étnica (específica), "la inseguridad cultural" y el dinamismo demográfico y la capacidad expansiva de la religiosidad musulmana.
\end{abstract}

Palabras claves: integración, asimilación, multiculturalismo, etnicización,república, islam, banlieues.

\begin{abstract}
This paper discusses the relevance of the gap between the republican integration doctrine and sociological, political, cultural and demographic dynamics of "ethnic" community relations that induce to a state of "multiculturalism in fact," a French multiculturalism. Unintended result of blind and hypocritical hegemonic regulation of the principle of civic unity of the nation, French multiculturalism can be submitted at least theoretically, as the confluence of five sub-processes: the ethnicization of urban space and the weakening of social bonds (lien social), territorial specialization and social relegation, the "politique de la ville" as ethnic policy (or specific policy), "cultural insecurity" and demographics dynamics and expansion capacity of the Muslim religion.
\end{abstract}

Keywords: integration, assimilation, multiculturalism, ethnicization, Republic, Islam, banlieues.

\section{Introducción}

La sociedad francesa de hoy está marcada por una doble fragmentación social (crise du lien social) y urbana constatables en los banlieues que acumulan dificultades estructurales propias de un urbanismo rápido y monofuncional y la pauperización y vulnerabilidad social de sus habitantes (Tshitshi Ndouba, 2012). La situación social de los inmigrantes e hijos de inmigrantes en Francia obliga a una mirada crítica de 30 años de políticas de integración, llamadas republicanas. "Todo el mundo está de acuerdo en lo mismo: elascensor socialno funciona en Francia. ¿Por qué se ha atascado esa mecánica de integración que durante cien años transformó hijos de mineros polacos, albañiles italianos, yeseros españoles 0 artesanos portugueses en empresarios, funcionarios, investigadores o inventores franceses? ¿Por qué los valores universales de la República no seducen, asimilan e integran por igual a 
quienes han llegado a Francia procedentes de distintos puntos de su antiguo imperio colonial ${ }^{1}$

El propio Primer ministro francés Manuel Valls, dará la respuesta más que oficial a estas preguntas, dos semanas después de los atentados yihadistas de Charlie Hebdo y del supermercado judío Hipper Casher, el 20 de enero. Denunció abiertamente en una comparecencia ante la prensa los males y las fracturas que consumen Francia y con una franqueza sorprendente sentenció que en Francia hay un apartheid social, territorial y étnico ${ }^{2}$, nombrando así la realidad por su nombre ${ }^{3}$.

Este reconocimiento muy tardío del fracaso de la política de integración republicana que hace hincapié en la integración política y en la creación de un sistema de identidad e igualdad formal, se inscribe en la lógica del declive, en los debates normativos y académicos en torno a la gestión de la diversidad cultural, del propio concepto de integración, como concepto aglutinador de una sociedad socialmente cohesionada y de garantía de paz civil. Con toda probabilidad, el proceso de remise en question del modelo de integración republicana abre el camino a un cambio de paradigma que apela más justicia social, articulado en torno al concepto de "sociedad inclusiva". El informe "La Gran Nación. Por una sociedad inclusiva" encargado por el Primer ministro Jean Marc Ayrault al Consejero de Estado Thierry Tuot, remitido el $1^{\circ}$ de febrero de 2013 es revelador de esta concepción rupturista que la izquierda francesa se propone aplicar al modelo francés de integración. Convencido que, en el contexto actual, el concepto de integración se ha quedado inadecuado y con una carga negativa para ser un objetivo político, Thierry Tuot (2013) argumenta que:

"Les défauts de l'intégration sont d'instrumentaliser ses destinataires en en faisant des sujets passifs, de supposer un parcours temporel qui se prête mal aux réalités des trajectoires personnelles hétérogènes, d'exiger de définir les publics qu'on sait observer mais pas subsumer sous une variable autre que celle dont on veut gommer les effets, qui stigmatise au moment où l'on veut que cesse le stigmate".

Teniendo presente esta perspectiva rupturista en el discurso político y antes de abordar las dinámicas sociológicas, culturales y demográficas que van sentando las bases, a nuestro juicio, de nuevo tipo de multiculturalismo sin respaldo político normativo, que llamamos el multiculturalismo a la francesa, conviene exponer el proceso histórico de construcción hegemónica del

\footnotetext{
${ }^{1}$ Octavi Marti, El ascensor social no funciona. Los valores de asimilación e integración que caracterizaron a la República fracasan con la población islámica y africana. El País, 10 de noviembre de 2005 http://elpais.com/diario/2005/11/10/internacional/1131577211 850215.html ${ }^{2}$ http://internacional.elpais.com/internacional/2015/01/20/actualidad/1421760687_753466.html http://www.lemonde.fr/banlieues/article/2015/01/26/manuel-valls-l-apartheid-et-les-

banlieues 4563754 1653530.html

${ }^{3}$ Declaró: "Sí, estos últimos días han puesto de relieve muchos de los males que consumen a nuestro país o los desafíos que tenemos que enfrentar. A esto, hay que añadir todas las fracturas, unas tensiones que llevan tiempo incubándose como la relegación en la periferia urbana, los guetos... lo que evocaba ya en 2005, un apartheidterritorial, social y étnico que se ha impuesto en nuestro país. A esta miseria social, se suman las discriminaciones diarias por no tener el nombre adecuado, el buen color de piel o ser mujer".
} 
paradigma de integración republicana que hasta la fecha es el modelo normativo de integración de los inmigrantes en Francia.

\section{El proceso histórico de construcción del paradigma de integración republicana}

Hasta la creación del Alto Consejo para la Integración por el Primer Ministro Michel Rocard en 1989, no existía, una "política" (en el sentido inglés de policy) para la integración de los inmigrantes. Prevalece entonces en Francia una filosofía pública de "ciudadanía igualitaria" basada en la lucha contra las discriminaciones, puesto que la clase política promueve "l'integration par défaut" partiendo de la convicción de que las discriminaciones y el racismo son los únicos factores susceptibles de impedir la "incorporación" exitosa a la comunidad francesa. Así, para integrar basta con remover las prácticas discriminatorias y reprimir las actitudes racistas. Por lo tanto, el modelo comúnmente llamado "a la francesa"(Schnapper, 1998; Beaujeu, 2008) se nutre de un enfoque pasivo que se articula en torno a dos instrumentos de carácter jurídico-político para canalizar la integración de los inmigrantes: la Ley de extranjería y la lucha contra las discriminaciones.

Los principios de igualdad cívica y de ciudadanía individual así como la importancia de la naturalización constituyen el pedestal sobre el que asienta el modelo francés de integración de los inmigrantes. Los debates sobre su evolución, y el eventual punto de inflexión en el desarrollo del modelo no cuestionan estos principios, sino que proponen visiones y matices en su aplicación frente a la realidad que vive la inmigración en Francia. Es en este sentido que se pronuncia la obra conclusiva de Jacqueline Costa-Lascoux publicada en 2009 sobre "La integración a la francesa: una filosofía a pruebas de las realidades".

De esta forma, desde los años 70, tanto los gobiernos de izquierda como de derechas, desarrollan una intensa actividad legislativa sobre derecho de extranjería que tiende a reforzarlo en sus aspectos policiales y el acceso a la nacionalidad francesa ${ }^{4}$.

${ }^{4}$ Durante el periodo de vigencia del modelo de integración a la francesa, podemos registrar al menos seis principales textos legislativos sobre extranjería

- La ley del 17 de julio de 1984 sobre la tarjeta única de residencia y trabajo:

- La Ley de 9 de septiembre de 1986 sobre las condiciones de entrada y residencia de extranjeros en Francia

- Ley de 2 de agosto de 1989 relativa a las condiciones de entrada y residencia de los inmigrantes en Francia, que enmienda gran parte de la Ley Pasqua de 1986.

- La Ley de Quiles de 2 de julio de 1992 relativa a la creación de áreas de "espera" en los puertos y aeropuertos.

- La Ley de 22 de julio de 1993, llamada la ley Méhaignerie, sobre la reforma de la ley de lanacionalidad.

- La Ley de 24 de agosto de 1993 que sigue en la línea de corregir algunos aspectos de la Ley Pasqua. 
En el aspecto referente a las reivindicaciones constantes de reconocimiento de la igualdad real, cristalizadas por las marchas por la igualdad y contra el racismo (Marche des Beurs) que llegaron a París el 3 de octubre de 1983, los poderes públicos orientaron sus actuaciones en dos direcciones: por una parte, tomando un conjunto de medidas dirigidas a remover los obstáculos y facilitar el acceso de las poblaciones inmigrantes y de origen inmigrante a las prestaciones sociales (acceso al derecho común- accès au droit commun). Es así que se concretó la supresión de la condición de nacionalidad para acceder al conjunto de prestaciones no contributivas ${ }^{5}$. También dos disposiciones legales, una de 16 de noviembre de 2004 relativa a la lucha contra las discriminaciones y otra de 30 de diciembre de 2004 de creación del la HALDE (Haute Autorité de Lutte contre les Discriminations et pour l'Egalité), vinieron a reforzar los dispositivos de lucha contra las discriminaciones y el racismo. Por otra parte, el eje de actuación de este enfoque de lucha contra el racismo se orientó hacia el reconocimiento jurídico y el apoyo financiero a las asociaciones promovidas por los inmigrantes en aras a defender sus intereses. Este eje ha sido problemático al dar cabida a posibilidades de repliegues identitarios y particularismos. El instrumento jurídico más importante que hizo posible la institución de los movimientos autocentrados de inmigrantes sobre la base étnica o geográfica fue la Ley de 9 de octubre de 1981 que liberalizó el régimen jurídico de las asociaciones de extranjeros ${ }^{6}$.

El principio de igualdad es el pilar mismo de la Revolución francesa y de la Declaración de los derechos del hombre y del ciudadano de 1789. Evoca las concepciones universalistas de los derechos naturales anteriores a las Constituciones de las sociedades políticas, que implican naturalmente la igualdad de todos los individuos ante la ley, independientemente de sus orígenes, razas y religiones. Este principio rechaza la lógica de representación colectiva de las comunidades en la sociedad civil, excluyendo por lo tanto la posibilidad de reconocer derechos colectivos de titularidad a una minoría. Ahora bien, muchas de las críticas que apuntan al fracaso de este modelo, tanto desde la arena política como periodística, aluden efectivamente a este fundamento y pretensión universalista de igualdad que solo sirve para obnubilar las desigualdades (Simon, 2003), principios universalistas que tienden a olvidarse cuando se trata de confrontarse con la realidad migratoria (Weil, 2005).

Ahora bien, el año 2002 marca un antes y un después en la evolución y la concepción de las actuaciones públicas en materia de acogida e integración de las poblaciones inmigrantes en Francia. En un discurso histórico sobre el futuro del Pacto Republicano pronunciado en Troyes el 14 de octubre de 2002, el Presidente Chirac anunciaba las bases de la nueva política, la llamada "política refundada de integración":

\footnotetext{
${ }^{5}$ Esto se debió en primer lugar, al esfuerzo de la jurisprudencia del Consejo de Estado en el ámbito de las prestaciones (por ejemplo, con la decisión del Consejo de Estado de 30 de junio de 1989, sobre el contencioso que opuso por una parte el Bureau d'Aide Sociale, ville de Paris y el Sr. Lévy, por otra parte) alineando así los extranjeros con el derecho común.

${ }^{6}$ Esta normativa deroga el régimen instituido por el decreto-ley de 12 de abril de 1939 sobre el estatuto especial de asociaciones extranjeras y asociaciones integradas por extranjeros, que exigía la autorización previa del Ministro de interior para la constitución de estas asociaciones.
} 
"Mais comprenons bien qu'au- delà du rétablissement de la sécurité et de la qualité de vie, l'égalité des chances suppose de donner une nouvelle vigueur à notre modèle d'intégration. Derrière ce mot d'intégration, les réalités sont multiples. Il y a la nécessité d'accueillir dans de bonnes conditions les nouveaux arrivants, ceux qui rejoignent notre pays légalement et qu'il faut aider à mieux s'insérer dans notre société. Je souhaite ainsi, qu'à l'instar de ce qui existe chez certains de nos voisins, chaque nouvel arrivant s'engage dans un véritable contrat d'intégration comprenant notamment la possibilité d'accéder à des formations et à un apprentissage rapide de notre langue"

Como se observa, este discurso marca una ruptura con las políticas anteriores de "integration par défaut", esencialmente basadas en un simple acompañamiento social de los trabajadores inmigrantes y sus familias y en la lucha contra las discriminaciones que han generado inevitables imágenes de exclusión social de la población inmigrante en Francia (precariedad social, profesional..). El espectro del Islam y la denuncia de los comunitarismos que amenazan la tradición republicana ayudan a comprender las evoluciones y cambios en el discurso. Del "modelo francés de integración" se transita hacia la "integración republicana" (Lochack, 2008, Costa-Lascoux, 2006). Al cambio del discurso le acompaña una multiplicidad de textos que incorporan y reiteran el concepto de República que es ya omnipresente. En el plano político aparece nítidamente el objetivo de refundar la política de integración a partir de la organización de la acogida de los recién llegados a través del contrato de integración, que por ende se convierte en un instrumento político clave y decisivo para el éxito del proceso de integración.

Por ello, a partir de este momento, la acción política para regular el proceso de integración se fundamenta en una relación contractual entre el recién llegado y la sociedad de acogida en términos de derechos y obligaciones. La integración refundada parte de la premisa de que desde la acogida debe exigirse al candidato a la residencia y trabajo en Francia un compromiso voluntarista de integración, al mismo tiempo que se constituyen modalidades de control del mismo respecto de los compromisos adquiridos.

En el desarrollo de este nuevo marco político para la integración, la definición de la integración dada por el Alto Consejo para la Integración, en su informe de 2006 sobre "Balance de la política de integración 2002-2005" refleja la concepción republicana de la nación basada en la libre elección de los ciudadanos de vivir juntos y en el respeto a los derechos individuales, valores fundamentales de la ciudadanía francesa:

“La integración...no es ni asimilación (...) ni inserción. Exige un esfuerzo recíproco, una apertura a la diversidad que es un enriquecimiento pero también una adhesión y una voluntad responsable de garantizar y construir una cultura democrática común".

Sin embargo, a partir de esta definición el Alto Consejo para la Integración reivindica que la política de integración ha de ser una política autónoma, independiente, con objetivos y medios de intervención propios y con cuatro características fundamentales: Es una política voluntarista, que ha de asegurar un equilibrio entre un conjunto de derechos fundamentales y unos elementos de una diversidad nuevaa la cual se ha de dar cobijo; la política de integración 
se asienta sobre la noción fundamental de contrato. Es una política global, aplicar un planteamiento holístico que tenga en cuenta no sólo los aspectos económicos y sociales de la integración sino también los problemas relacionados con la diversidad cultural y religiosa, la ciudadanía, la participación y los derechos políticos (Comisión Europea, 2003).

Teóricamente, el paradigma de la integración republicana emerge en 1998 puesto los informes del Alto Consejo para la Integración anteriores a 1998 no hacen referencia ni a la República ni al modelo republicano. El vocablo "República" se evoca por primera vez en el informe de 1998 sobre la escuela (l'Ecole Républicaine). La verdadera aparición de la "República" data de 2001, cuando el Alto Consejo decide interesarse por el "Islam en la República" y estudiar la compatibilidad entre la religión musulmana y los valores republicanos -entre los que el laicismo es uno de los más importantes-, así como por las posibilidades de combinar la expresión de pertenencia a una religión con el respeto a las reglas de funcionamiento de la escuela republicana. Con el informe de 2004 sobre "El contrato y la integración" se da un paso más al abordarse no solamente la escuela republicana sino también la "filosofía republicana", una "instrucción auténticamente republicana", el "régimen republicano", la "ambición republicana" (de un tratamiento igual para todos), el "derecho político republicano de la ciudadanía", la "ley común republicana", el "contrato republicano", etc. (Lochak, 2008).

Así, bajo la influencia de la tradición republicana francesa, inevitablemente los teóricos de la política de integración en Francia establecen un nexo entre la noción del pacto republicano y el contrato de integración. Más aún, reconducen la noción de contrato de integración a los fundamentos del derecho político republicano de la ciudadanía y del Pacto Social. En estos términos, se apoyan en el contrato social que redefine la relación entre la Ley y el Derecho. La Ley es un mandamiento coercitivo para el individuo y el Derecho se convierte en una libertad y una utilidad para este mismo individuo $(\mathrm{HCl}, 2003)$.

Desde la perspectiva del Alto Consejo para la Integración (2006), la filosofía de la integración republicana tiene sus fundamentos en la definición de la nación como una unidad cívicaque alberga en su seno una diversidad cultural muy amplia y una comunidad de ciudadanos:

"Esta comunidad se justifica no solo por la historia, por los relatos y símbolos republicanos, en otros términos, por la herencia de lo dado por el pasado, sino que tiene como pilar la idea de contrato, es decir, lo construido. A partir de esta idea, la comunidad de los ciudadanos no es una comunidad étnica ni racial. No se nace ciudadano sino que se deviene ciudadano. La consecuencia de este contrato implícito es que a través de él, se transita de la muchedumbre indiferenciada, particularista, a la unidad de un pueblo, una colectividad reunida".

A partir de estos planteamientos filosóficos del pacto republicano, el Alto Consejo proporciona más contenido a la integración republicana:

"integrar es ante todo consentir y adherirse a la Ley común, que garantiza a todos los ciudadanos los derechos fundamentales. Toda persona que accede a la ciudadanía francesa, fundada sobre el pacto republicano, ha de beneficiarse del conjunto de los derechos políticos, siendo protegida como ciudadana. A 
cambio, ha de ser consciente de sus deberes de cara la comunidad y de su obligación moral de contribuir al mejor destino de la nación y participar en la materialización de la cohesión social de la nación".

Así la filosofía republicana de la integración rechaza la idea de la asimilación, una manifestación de violencia cultural hacia el colectivo de ciudadanos de origen cultural minoritario en el espacio público común, obligándolo a renunciar a su cultura propia y a adoptar los patrones de la cultura mayoritaria del pueblo francés. Más aún, en el discurso político francés, la asimilación que evoca demasiado la empresa colonialista, se deslegitimó hace tiempo, sobre todo porque en la escena pública, la asimilación fue reducida al asimilacionismo (Schnapper, 1998). El descredito y declive de la modalidad asimilacionista de incorporación a la comunidad francesa se debe enormemente, según Mirna Safi (2007) a dos factores y movimientos relativamente alejados del asunto migratorio: por una parte el regionalismo y por otra el anticolonialismo. En Francia, el militantismo regional ganó terreno en los años 70 acusando, por ende, al Estado jacobino de haber erradicado las culturas particulares en beneficio de la cultura dominante. Por otra parte, muchos han visto en la experiencia de la asimilación un proceso de alineamiento de los comportamientos de los colonizados a las normas y valores de la civilización occidental, suponiendo ello un rechazo de una cultura en favor de otra y una superioridad de la cultura occidental sobre la cultura autóctona.

Ahora bien, para dar contenido al concepto de integración republicana, los ideólogos del Alto Consejo para la integración recurren a las ideas de Jurgen Habermas $(1991)^{7}$ sobre la concepción republicana de la democracia. En efecto, Habermas postula que contrariamente a la concepción liberal de la democracia

"el status de ciudadano no viene definido por este esquema de libertades negativas de las que los ciudadanos pueden hacer uso como personas privadas. Los derechos ciudadanos, entre los que sobresalen los derechos de participación y comunicación política, son más bien concepciones positivas. No garantizan la libertad respecto de coerciones externas, sino la participación en una práctica común, cuyo ejercicio es lo que permite a los ciudadanos convertirse en aquello que quieren ser, en sujetos políticamente responsables de una comunidad de libres e iguales".

Desde estas premisas, la concepción francesa de la integración republicana distingue dos dimensiones del concepto de integración: la integración ética (o cultural) y laintegración política. Esta concepción rechaza la integración ética ya que sería inconcebible, contraproducente y éticamente reprobable exigir una integración ética a un ciudadano francés de origen inmigrante, es decir, exigirle que renuncie a los componentes de su cultura de origen. En cambio, la integración republicana exige una integración política, entendiéndose por ello la integración en una cultura política común definida por la Constitución y la Ley común. Estos planteamientos de la filosofía de la integración republicana

\footnotetext{
${ }^{7}$ Conferencia sobre "Tres modelos de democracia. Sobre el concepto de una política deliberativa", pronunciada en el Departamento de Filosofía de la Universidad de Valencia el 16 octubre 1991. http://www.alcoberro.info/V1/habermas7.htm
} 
concluyen, pues, que esta cultura política común se materializa a través del contrato, del derecho y de la ley republicana.

Por otra parte, inspirándose en las ideas de Giovanni Sartori (2004) sobre la sociedad multiétnica, la integración republicana rechaza frontalmente la concepción comunitarista o diferencialista de la integración arguyendo que aunque las tradiciones culturales juegan un papel fundamental en el desarrollo y la promoción de la identidad individual, cualquier tradición cultural no se justifica por sí misma. En caso de colisión entre una cultura tradicional y la identidad política común fundada sobre el Derecho y la Ley, es esta cultura tradicional la que ha de adaptarse. Además, como lo afirma el propio Alto consejo para la Integración, ninguna cultura permanece inmutable y ninguna tradición del pasado tiene autoridad y valor en la República cuando infringe los derechos individuales. El ser humano no solo tiene una identidad cultural, también tiene una identidad política. Más aún, el hecho de reconocer derechos específicos a una comunidad dada atenta contra el principio de igualdad republicana.

A partir del principio de la unidad cívica y la concepción electiva de la nación, el paradigma de la integración republicana ha sido llevado a su culminación y punto hegemónico con inclusión en su cuerpo doctrinal de elementos de una concepción etnosimbolica de la "identidad nacional" (Koukoutsaki-Monnier, 2010), tal y como ha sido sistematizado por Nicolás Sarkozy en sus discursos electorales, y su filosofía plasmada en la creación del polémico Ministerio de inmigración, identidad nacional y codesarrollo.

En efecto, las conceptualizaciones de la correlación entre inmigración e identidad nacional hechas por Nicolás Sarkozy y la derecha francesa no se han circunscritas en los límites de la concepción cívica y electiva de la nación, siendo esa ultima un proyecto voluntarista de futuro común. El discurso político de Sarkozy sobre la identidad nacional sienta las bases de una concepción etnosimbolica de la nación. Desde esta perspectiva, la nación no es vista simplemente como comunidad que posee un cierto número de características vinculadas a su origen étnico, sino como comunidad que experimenta procesos de adquisición de estas características. A través de este proceso, los recursos culturales preexistentes en la comunidad tales como las memorias, los mitos, los símbolos, los valores y las tradiciones "se nacionalizan". De una visión estática, pasamos así a una visión dinámica de la nación: ésta no emerge naturalmente en momento dado de su historia sobre la base de una etnia preexistente, sino que es resultado de procesos socioculturales interactivos por los que los miembros de una comunidad adquieren una identidad específica; un grupo social se hace una nación bajo un conjunto de condiciones precisas (Koukoutsaki-Monnier, 2010). La identidad nacional entonces es definida, según las palabras de Anthony Smith (2003), como "el mantenimiento y la incesante reinterpretación de un conjunto de valores, símbolos, memorias, mitos y tradiciones que forman la herencia distintiva de la nación, así como la identificación de los individuos con esta herencia".

Todo ello nos lleva a la cuestión crucial de la inmigración que es para Nicolas Sarkozy, al fin y al cabo, el elemento amenazante y distorsionante de la identidad nacional francesa. Sarkozy no puede ser más claro sobre este tema. El primer elemento con el que se vinculan la inmigración y la identidad nacional 
tiene que ver con el lazo afectivo y sentimental con Francia: Querer a Francia. Desde aquí, los problemas ligados a la inmigración y la mala integración, sin hacer referencia a las experiencias de discriminación y de racismo, tienen sus raíces en el odio y la rabia que un número importante de inmigrantes y de franceses de origen inmigrante tienen hacia Francia:

"A ceux qui n'aiment pas la France, qui ne la respectent pas, qui ne respectent pas ses valeurs, qui ne respectent pas ses lois, qui ont le sentiment qu'ils ne lui doivent rien, qui ne se reconnaissent à son égard aucune dette, aucun devoir, à ceux-là je veux leur dire qu'ils ne sont pas obligés de rester, qu'ils peuvent s'en aller chercher des pays plus libres, plus accueillants, plus généreux, plus tolérants s'ils en trouvent". (Nicolas Sarkozy, Discours à Saint-Quentin, 25/01/07, Discours au Futuroscope à Poitiers, 26/01/07)

Naturalmente, el supuesto odio de la inmigración se traduce en un no compartir los valores o compartir otros que son contrarios a los fundamentales de Francia. Así se pronuncia Sarkozy en su discurso de Chapelle-en-Vercors, el 12 de noviembre de 2009:

"Devenir Français, c'est adhérer à une forme de civilisation, à des valeurs et à des mœurs. La France est une terre de liberté et d'égalité. La France est un pays d'émancipation où chacun aspire à s'élever selon ses talents, ses mérites, son travail. La France est un pays où la femme est libre. La France est un pays où l'Église est séparée de l'État, où les croyances de chacun sont respectées. Mais la France est un pays où il n'y a pas de place pour la burka, où il n'y a pas de place pour l'asservissement de la femme, sous aucun prétexte, dans aucune condition et dans aucune circonstance. La France est un pays où il n'y a pas de place pour la confusion du spirituel et du temporel".

Todos estos planteamientos se conjugan en un intento de fundamentar y justificar políticamente algunas medidas a tomar sobre la política migratoria: techos y cuotas anuales, reagrupación familiar, conocimiento de la lengua, sin olvidar las referencias a la historia y a la cultura francesa, que serán lógicamente incluidas en los contratos de acogida e integración.

Los elementos aquí presentados apuntan pues a una visión etno-centrada de la identidad nacional. Tal y como concluye Koukoutsaki-Monnier (2010), todo el discurso de Sarkozy sobre la identidad nacional expresa una aceptación de la diversidad y una cierta apertura pero apela insistentemente a los fundamentos del pasado. Así, el discurso de Sarkozy es realmente la afirmación de un conjunto de recursos culturales e históricos, en el cual la herencia republicana es parte importante.

\section{Las argucias de la asimilación}

Desde su llegada al poder en 2012, el gobierno socialista ha emprendido un proceso de "remise en question" que apunta la voluntad política rupturista con la integración "refundada" iniciada por Jaques Chirac y cuya dimensión republicana ha sido reforzada por la era Sarkozy (las leyes Sarkozy de inmigración y la doctrina vinculando inmigración e identidad nacional). La nueva 
opción política anunciada gira en torno al concepto de "sociedad inclusiva", que se asemeja más al principio de inclusión social contenido en el PECI II ${ }^{8}$, puesto que apunta a procesos de creación de las condiciones necesarias para que sea posible una sociedad más igualitaria en términos socioeconómicos. Según esta conceptualización, los procesos de inclusión social han de llevar a superar las desventajas sociales, económicas, personales y culturales, permitir gozar de los derechos sociales y ejercer la participación ciudadana, superando el estatus de persona asistida y la estigmatización que conllevan la pobreza, la marginación y la exclusión (Ministerio de Trabajo e Inmigración, 2011). Thierry Tuot (2013) propone por lo tanto una política de refuerzo de capacidades, más que una política de integración:

"Il faut compenser les réactions de rejet et de refus (discrimination, incompréhension, peur, a priori...; il faut partager - culture, espace ; il faut rompre les frontières invisibles, de part et d'autre. L'ensemble de ces actions vise à la même chose: une mise en capacité."

Estas formulaciones de Thierry Tuot, aunque no han sido apropiadas por el gobierno francés, han estructurado los principios rectores en torno a los cuales el gobierno socialista se proponía construir el nuevo modelo y han inspirado profundamente los informes finales de los cinco grupos de trabajo $^{9}$ (compuestos por entidades locales, movimientos asociativos, universitarios, sindicatos y operadores económicos) instituidos para reflexionar y dar cuerpo al nuevo proyecto político de integración de los inmigrantes. La presentación oficial por el Primer Ministro francés Jean-Marc Ayrault el 11 de febrero de 2014 de la "hoja de ruta"10 del gobierno sobre "Política de igualdad republicana y de integración", se inscribe en este proceso de político para la (segunda) refundación de la política de integración, anunciado por el Primer ministro en su declaración de política general ante las cámaras francesas en febrero de 2013. Es el inicio (aunque tímido) de un cambio de paradigma consistente en poner más énfasis en las interacciones entre la sociedad receptora y los inmigrantes interesándose particularmente en las dimensiones o factores de la desigualdades socio-económicas.

En el contexto francés, los debates mediáticos, académicos y políticos, no exentos de polémicas y controversias, en torno a la eficacia y la funcionalidad del modelo integracionista/asimilacionista tienen dos registros: por una parte el carácter de asimilables y/o no asimilables de las sucesivas oleadas migratorias en Francia por la proximidad cultural y religiosa y por otra parte la hipocresía y

\footnotetext{
${ }^{8}$ EI Plan Estrategico de Ciudadanía e Inmigración II del gobierno de España añade uno nuevo principio a los tres del PECI-I: el principio de inclusión. EI PECI II sigue considerando que los principios son los ideales y valores propios de una sociedad democrática y de un Estado social de derecho, que aportan las líneas políticas que inspiran y dan coherencia al Plan Estratégico y a todas sus líneas de actuación. Estos principios son la igualdad, la ciudadanía, la inclusión y la interculturalidad.

9Grupo de trabajo "conocimiento-reconocimiento" (cultura, historia y memoria)- Grupo de trabajo "Hacer sociedad" (ciudadanía, servicios públicos y dialogo con la sociedad civil)- Grupo "hábitat" (segregación urbana, vida rural y movilidad geográfica)- Grupo de trabajo "Movilidades sociales" (educación, empleo y formación profesional)- grupo de trabajo "Protección social" (cuestiones relativas a la protección social).

${ }^{10}$ http://www.irev.fr/actualit\%C3\%A9/refondation-politique-dint\%C3\%A9gration-remise-rapports5-groupes-travail
} 
la argucia del proyecto asimilacionista en la aplicación del principio del principio de igualdad (formal y real) a la inmigración.

Es normal que en un contexto de predominio de los principios ideológicos republicanos de integración, la única explicación plausible del fracaso de integración tenga que ver con la falta de voluntad o la ineptitud del inmigrante a integrase en los moldes de la sociedad francesa. El argumento de la inasimilidad de la inmigración de Trente Glorieuses (1945-1974) y de Trente Perilleuses (1974-2005), se reduce a la distancia cultural y religiosa (extra europea y musulmana). Los inmigrantes procedentes de las ex colonias del Maghreb, el África subsahariano y Sur este asiático plantean resistencia a la asimilación, y por ende son declarados "los inasimilables".

Michèle Tribalat (2013) por ejemplo sostiene que la asimilabilidad de las migraciones intra-europeas de mediados del siglo XIX bajo el Segundo Imperio (1851-1870) hasta la Segunda Guerra Mundial, compuestas por italianos, belgas, españoles, portugueses alemanes, polacos y rusos (Lesquin, 2006, Noriel, 1988) es prueba de la funcionalidad práctica de dos dispositivos socializadores que articulan la integración a la francesa: La escuela republicana y laica, generalizadora de la lengua, la historia y los símbolos de la nación (Ley Ferry de 1882) y el ejército, La Grande Armée como instrumento decisivo de socialización nacional en la Grande Nation. Según este registro, estos inmigrantes supieron diluirse en el créuset français y se asimilaron exitosamente en las instituciones francesas por la proximidad cultural $y$ religiosa.

En todo caso, el argumento de proximidad cultural y religiosa (europeos y cristianos) no es decisivo. La capacidad demográfica y de absorción era evidente a la vista de la magnitud más o menos limitada de la oleada migratoria de la época, cosa que no tiene paralelismo en la inmigración de posguerra. En efecto, entre finales del Segundo Imperio y los albores de la Gran Guerra, Francia registra algo más que un millón de extranjeros: 420.000 italianos, 290.000 belgas, 100.000 españoles y 100.000 alemanes. En 1931, la población extranjera crece y se triplica, alcanzando la cifra de 2,9 millones sobre un total de 41,8 millones de franceses. Los italianos siguen siendo los primeros en el ranking con 808.000 ciudadanos, seguidos de los polacos que llegan a 508.000. Se registran también 352.000 españoles, 250.000 belgas y 100.000 suizos (Lesquin, 2006). Dos factores contribuyen a la asimilación: el contexto de bonanza económica que crea más oportunidades de movilidad social y la aceptación y clima de no rechazo por parte de los autóctonos.

Este argumento desarrollado por Tribalat (Ibis) descansa en el hiatus o la brecha cultural entre el mainstream society y las nuevas oleadas migratorias en Francia, alejándose de las dimensiones estructurales de las desigualdades socio económicas que relegan a las ciudades duales (Lorenzo Cachón, 2010). En el contexto francés, la prohibición de estadísticas étnicas (no reconocimiento de la presencia de minorías étnicas en el espacio público) constituye un obstáculo serio a la objetivización del conocimiento sociológico de la integración de los inmigrantes, al circunscribir el análisis de las desigualdades desde las prismas de la estratificación social (estatus y clases), deslegitimando los enfoques basados en la estratificación étnica de la sociedad francesa (Safi, 2007). 
Así, la normatividad de la doctrina de integración republicana impide estudios empíricos y longitudinales que establezcan las pertinentes correlaciones entre las dimensiones culturales y estructurales (empleo, matrimonios mixtos, segregación residencial...) de la asimilación de los inmigrantes a la sociedad francesa, tal y como lo sugiere el marco teórico de la asimilación segmentada propuesto por Gordon Milton (1964). Por lo que falta una radiografía real y documentada de las dimensiones excluyentes de la sociedad francesa.

Los informes del Observatorio de las 751 Zonas Urbanas Sensibles (a lo largo del territorio francés) pueden visualizar a titulo tentativo las magnitudes de las desigualdades que afectan a los inmigrantes y sus descendientes. Según el informe ONZUS $2011^{11}$, del total de 4,5 millones de habitantes de los territorios ZUS, el 56,6\%, es decir algo más de la mitad, son inmigrantes o de ascendencia inmigrantes. En las ZUS de la región parisina, el porcentaje de personas de ascendencia migratoria alcanza el 64\% (Los magrebís ocupan el primer puesto de este ranking, mientras los inmigrantes procedentes de Vietnam, Laos y Camboya son minoritarios). En cuanto a la situación laboral, el $19,2 \%$ entre los inmigrantes y el $28,6 \%$ de sus descendientes se encuentran desempleados. Los que trabajan ocupan los oficios menos cualificados, alcanzando el $52 \%$ de obreros y tan solo $4,4 \%$ de empleo cualificado y cuadros de mando. En cuanto a los datos de percepción, del total de los habitantes de territorios ZUS, 40\% entre los inmigrantes y 97 entre sus descendientes han adquirido la nacionalidad francesa, pero tan solo el $57 \%$ creen que son percibidos como franceses mientras que fuera de las zonas ZUS esta percepción alcanza el 78\%.

\section{Los subprocesos de un multiculturalismo a la francesa}

Las tesis multiculturalistas originan a día de hoy fuertes controversias tanto a nivel académico como en el campo político (Parsanoglou, 2006). En el ámbito académico, el multiculturalismo recibe varios significados, a veces contradictorios y no exentos de valoraciones ideológicas. De antemano, los distintos posicionamientos responden a las concepciones que los autores tienen de las culturas por una parte, y por otra, a las repercusiones de esta concepción sobre la integración y la cohesión de la sociedad. Los autores liberales/conservadores (Huntington, 1997, Sartori, 2004, Barry, 2001), anclados en la perspectiva del reduccionismo cultural, tienen una visión monolítica o estática de la cultura, mientras otros autores de corte marxista (Foucault, Kymlica, Hardt y Negri, Zizek), ven en el multiculturalismo una lógica de "exclusión" cultural/racial y una estrategia de promoción del capitalismo global.Sartori mismo(2006) reconoce que la versión dominante del multiculturalismo es una versión antipluralista cuyos orígenes intelectuales son marxistas. Afirma que antes de llegar a Estados Unidos y de americanizarse, el multiculturalismo arranca de neomarxistas ingleses, a su vez fuertemente influenciados por Foucault; y se afirma en los colleges, en las universidades,

\footnotetext{
${ }^{11}$ http://www.ville.gouv.fr/IMG/pdf/rapport_onzus_2011.pdf
} 
con la introducción a los "estudios culturales" cuyo enfoque se centra en la hegemonía y en la dominación de una cultura sobre otras.

Así, las críticas hacia el multiculturalismo han sido abundantes y todo indica que las políticas multiculturalistas han fracasado y han sido abandonadas oficialmente por los Estados que las abanderaban. La frase dilapidaría "Multiculturalism iso ver", pronunciada por el propio Phillips Trevor, Director de la Human Rights and Racial Equality Commission del Reino Unido, organismo defensor de la política multiculturalista, no puede ser más elocuente al respecto.

Por otra parte, desde el punto de vista teórico y doctrinal, muchos autores, desde la óptica liberal, han demostrado que los intentos de Will Kymlica (1999) de teorizar sobre el multiculturalismo liberal, es decir de asociar el concepto de multiculturalismo y liberalismo (en tres categorías o grupos: poblaciones indígenas, entidades minoritarias subestatales y grupos de inmigrantes) no se sostienen racionalmente. En efecto, como lo afirma Christian Joppke (2004) en su interesante ensayo titulado "The retreat of multiculturalism in liberal states: theory and policy", desde la perspectiva liberal las políticas multiculturalistas tienen efectos negativos para una sociedad que se quiere integrada y cohesionada. El reconocimiento de las diferencias y la atribución de derechos diferenciales, así como la prácticas compensatorias o discriminación positiva a favor de los grupos o minorías étnicas o culturales suponen no solo una ruptura fáctica del principio funcional de la igualdad individual e institucional, sino también el debilitamiento de la identidad cívica compartida y del nivel de compromiso de los miembros de esa sociedad (Kymlica y Straehle, (2000), Calderón Vázquez (2009). La preocupación de los autores liberales sobre los efectos nocivos de las políticas multiculturales puede verse claramente a través de los escritos de Barry (2001), quien contrapone los intereses de los grupos con los intereses de la sociedad. Este autor considera que el énfasis de las políticas multiculturalistas en la diferencia trae consigo un refuerzo de los hechos diferenciales que ahonda las distancias en vez de acortarlas. Esto supone que los distintos grupos etnoculturales puedan tender a encerrarse en sí mismos, enrocándose en torno a "su" hecho diferencial y tendiendo a interactuar solo consigo mismos. Se produce en paralelo una baja interacción con los restantes grupos sociales y con la sociedad en su conjunto, impidiendo que surja un horizonte común, un proyecto común de sociedad con el cual puedan identificarse los individuos. Si cada grupo pretendiera la existencia de políticas hechas a su medida, destinadas a satisfacer "sus" necesidades, el conjunto, o mejor dicho la cohesión del mismo, podría resentirse, cuarteándose el conjunto del sistema. Por tanto, para Barry van a resultar incompatibles la perspectiva de grupo con la de sociedad cuando el primero se antepone a la segunda (Calderón Vázquez, 2009).

Ahora bien, en el contexto francés, el movimiento del gobierno socialista hacia la opciónpolítica de sociedad inclusiva, es un reconocimiento del estado de "multiculturalismo de hecho", que es el resultado no deseado de la normatividad hegemónica de la doctrina de integración republicana. Así, el "multuculturalismo de hecho", no tiene nada que ver con el reconocimiento de 
la multiculturalidad de la sociedad, ni tampoco con el multiculturalismo como proyecto político normativo.

El estado de "multiculturalismo de hecho" o multiculturalismo a la francesa es producto de las dinámicas de las relaciones comunitarias étnicas en Francia que, confirmando los postulados de la teoría de la etnicidad desarrollada por Max Weber(1993) se manifiesta en tres dimensiones: Las relaciones étnicas, al implicar categorías étnicas son cuestiones de creencia que proceden à clasificar los individuos en grupos, en función del origen supuesto (o real), que determinaría al fin y al cabo una identidad profunda. Y la consecuencia más inmediata de estas clasificaciones es la adscripción, a cada categoría, de un juicio de valor que desvaloriza el grupo visto como diferente, el outgroup, y al contrario, exalta la dignidad y el honor del grupo de pertenencia. Por lo tanto, el multiculturalismo de hecho tiene su fundamentación en la etnicización de las relaciones sociales que se ha desarrollado en Francia.

\section{Postulados teóricos del multiculturalismo a la francesa}

Desde nuestra perspectiva, arguyamos que teóricamente, el multiculturalismo a la francesa, puede sustentarse sobre dos postulados:

En primer lugar, se trata de un estado intermedio entre la multiculturalidad y multiculturalismo normativo, es decir, entre lamulticuluturalidad de la sociedad, entendida como la coexistencia en un mismo espacio socio-territorial de individuos y grupos de individuos pertenecientes a distintas etnias, culturas y nacionalidades, una constatación de la pluralidad de identidades y de diversidad etnocultural (Calderón Vázquez, 2009; Cortina, 2005 y Arango, 2002); y el multiculturalismo como proyecto político normativo, que aboga por el respeto, reconocimiento en el espacio público y la promoción activa de la identidad cultural de las minorías étnicas, negando por ende, los intentos uniformizadores de la asimilación hacia culturas mayoritarias (Sartori, 2004, Kimlyca, 1999).

En segundo lugar, el multiculturalismo a la francesa es un estado sociológico y un output resultante de las dinámicas complejas de las relaciones y de los procesos históricos y sociales que se derivan del asentamiento de la inmigración de postguerra en la sociedad francesa.Siguiendo el esquema del modelo relacional elaborado por Cristina Blanco Valderrama (1993), El multiculturalismo a la francesa se evidencia a partir de los estudios empíricos específicamente circunscritos en tres dimensiones o condicionantes:

- $\quad$ Condicionantes estructurales del asentamiento residencial (dispersión o concentración étnica) y de la integración laboral o educativo.

- Condicionantes intergrupales: características de los grupos que interaccionan, tanto de los autóctonos como los inmigrantes en cuanto a similitud (racial, étnica y/o cultural), familiaridad y conciencia étnica.

Actitudes mutuas: de aceptación o rechazo por parte de los autóctonos y de los inmigrantes en torno a la inmigración, los inmigrantes y el tipo de 
integración. Estas actitudes afectan directamente a la naturaleza del contacto y condicionan la acción política en torno a la inmigración.

\section{Dinámicas de etnicización de las relaciones sociales y culturales como presupuestos del multiculturalismo a la francesa}

La etnicización alude al proceso (social, histórico y político) de construcción de fronteras y de designación de los grupos sociales, definidos (socialmente) o que se autodefinen por su origen o cultura. En sociología, etnicización no implica indagar la existencia de un grupo como étnico, sino más bien, hacer hincapié en el carácter relacional o construido de tal grupo o categoría de personas (Primon, 2007). Desde nuestro punto de vista, el multiculturalismo a la francesa, puede presentarse por lo menos teóricamente, como la confluencia de cinco subprocesos: la etnicización del espacio urbano y el debilitamiento del vinculo social (lien social), la especialización territorial y la relegación social, la "politique de la ville" como política étnica (específica), "la inseguridad cultural" y el dinamismo demográfico y la capacidad expansiva de la religiosidad musulmana.

\subsection{Un subproceso sociológico: La etnicización del espacio urbano y el debilitamiento del lazo social}

En Francia, el proceso de etnicización de las relaciones sociales se inicia con la política de concentración de la población inmigrante o de origen inmigrante en las zonas urbanas periféricas que concentran viviendas sociales (HLM), banlieues, convertidos más tardes en zonas sensibles, socialmente descalificadas por albergar en su seno todos los indicadores de vulnerabilidad social (Wieviorka, 1996) . Este proceso urbanístico discriminatorio conlleva una lógica de encerramiento cultural a partir de la definición de categorías de población, identificados por características fenotipos, apariencias físicas, modos de vida, tradiciones o creencias (Costa-Lascoux, 2001), que finalmente desemboca en la asignación de una identidad.

La etnicización del espacio urbano, al concentrar una categoría sociológica, que además de étnica, es expuesta a la precariedad económica y social cada vez mayor en unos límites territoriales, es factor determinante de ruptura del lazo social (lien social) que a su vez lleva a la exclusión social. Conviene resaltar que las causas de debilitamiento (affaiblissement) del lazo social, no apuntan a la pobreza, sino que se sitúan en la tradición francesa acerca de la exclusión social que Hilary Silver, citado por Mauricio Rojas (2011), define como:

"un proceso dinámico de ruptura multidimensional del lazo social a nivel individual y colectivo. Por lazo social entiendo las relaciones sociales, las instituciones y las identidades imaginadas de pertenencia que constituyen la cohesión, la integración o la solidaridad social. La exclusión social impide la plena participación en las actividades normativamente prescritas de una sociedad determinada y niega el acceso a la información, los recursos, la sociabilidad, el reconocimiento y la identidad, erosionando la autoestima y reduciendo las capacidades para alcanzar metas personales." 
En efecto, la precariedad económica y la inactividad laboral de los inmigrantes confinados, por voluntad política en los banlieues tienen, según el Alto Consejo para la Integración ( $\mathrm{HCl}, 1999)$ tres consecuencias mayores, que de hecho son las bases configuradores de unas sociedades aisladas e incomunicadas, dentro de la sociedad francesa.La primera es el debilitamiento de las estructuras familiares. En efecto, además de la imagen negativa que los padres parados de larga duración pueden producir en sus hijos, y que hace que estos padres pierdan autoridad, habrá que añadir las dificultades sociales que encuentra un número cada vez mayor de familias monoparentales para realizar un seguimiento responsable de los rendimientos de los hijos en el ámbito escolar. El debilitamiento del rol social de la familia hace que los menores que pasan mucho tiempo en la calle adquieran otros modos de vida y desarrollen otros tipos de comportamientos o de relaciones con el entorno no familiar o escolar. Lo que conduce la juventud inmigrante de los banlieues a la pérdida de toda referencia positiva y de las reglas fundamentales de la vida social como pueden ser el respeto a los demás, las reglas de disciplina colectiva sin las cuales no hay vida en común o el respeto a la autoridad pública de la ciudad. Este debilitamiento en la transmisión de los valores se manifiesta en el incremento de la violencia en el ámbito escolar, así como en la pérdida de todo sentido del esfuerzo y del trabajo.La segunda consecuencia que la situación de paro prolongado tiene sobre los hijos tiene que ver con el rendimiento y el éxito en el ámbito escolar. Los menores pueden renunciar al esfuerzo puesto que no verán un vínculo directo entre el éxito escolar y el empleo, perdiéndose el sentido del esfuerzo.La tercera consecuencia, es la posible crispación recíproca en la convivencia entre inmigrantes y autóctonosdel barrio. Estos ultimos culparán a los inmigrantes de ser los responsables de la degradación, mientras que a su vez los inmigrantes podrán percibir la actitud de los autóctonos como racista y discriminatoria.

\subsection{Un subproceso de geografía urbana: Especialización territorial y relegación social}

Siguiendo los postulados de la teoría de zonas circoncentricas (Park y Burgess, 1925),La geografía urbana de las grandes metrópolis francesas configura zonas duales distribuidas unas en espacios y territorios especializados de dinamismo económico, de creación de riqueza y otras de relegación social que aglutinan "los males de la ciudad". Esta especialización territorial de las grandes metrópolis ha expulsado también a las clases populares francesas y de la vieja inmigración, quiene, al no poder sufragar los costes altos de las viviendas en los centros de la metrópolis y no querer tampoco compartir espacios con la nueva inmigración en los banlieues, se ven forzados a dirigirse hacia nuevos conjuntos sociológicos de la "Francia periférica", compuesta, según Guilluyy Noyé (2004), por algo más que 34.000 ayuntamientos, con alrededor de 60\%franceses de vieja cepa (français au carré). Los dos autores llaman este proceso la "guetoización desde arriba":

"Cette "ghettoïsation par le haut" dessine dans le même temps une "France périphérique", ignorée de la sphère politique et culturelle, alors qu'elle est largement majoritaire. Elle unit des catégories sociales autrefois opposées l'ouvrier en milieu rural, le petit paysan, l'employé d'un lotissement pavillonnaire 
bas de gamme et le chômeur de banlieue subissent aujourd'hui le même sentiment de relégation. La précarisation des couches populaires, en effet, s'étend désormais aux classes intermédiaires, comme en témoigne la dégradation des conditions de vie dans les nouvelles banlieues de lotissements pavillonnaires ou dans les villes nouvelles, conçues dans les années 1960 pour les classes moyennes".

La consecuencia más inmediata de este apartheid social, territorial y étnico, además de la falta de interacción y de comunicación, es la fractura y el separatismo hacia abajo, es decir entre las clases populares en función del origen étnico. Los franceses al cuadrado (français au carré), relegado a la periferia, son hoy el electorado que más simpatiza con el Frente Nacional, se sienten abandonados por la clase política y la elite francesa (que vive en los centros de las grandes metrópolis), que flirtea por intereses electorales con las "minorías étnicas" de los banlieues, invirtiendo excesivamente en la política de renovación urbana y olvidándose del empowernement ${ }^{12}$ social (Kokoreff y Lapeyronie, 2013)

Ahora bien el cleavaje territorial y socio-étnico conduce a los habitantes de los banlieues a interiorizar la segregación y a desarrollar un modo de funcionamiento colectivo para adaptarse o resistir a las desigualdades e injusticias. Bajo esta lógica, emerge y se desarrolla nuevas formas de solidaridad, y segurización de los "relegados" al margen de la organización pública. Por lo tanto, el debate público sobre el comunitarismo el repliegue identitario, entendido como modo de vida de una comunidad minoritaria, que resiste o rechaza los principios republicanos de libertad, laicismo del estado e igualdad, y por ende reclama su reconocimiento e intervención en el espacio público (Keslassy, 2011) hace un amalgama entre comunitarismo y funcionamiento comunitario. Este último es el modo en el que la comunidad crea sus propios recursos y busca respuestas, en el marco que le proporciona seguridad por el hecho de su no reconocimiento en la sociedad (Carlon y Dessis, 2014).

\subsection{Un subproceso politologico: Las políticas públicas territorializadas}

Los principios de igualdad republicana, de unidad e indivisibilidad de la República impiden cualquier actuación pública dirigida a una franja de la ciudadanía seleccionada sobre la base de su origen étnico. En el seno de República, una y indivisa, solo caben políticas compensatorias de las desigualdades, políticas que tienen como objetivo compensar las diferencias en los niveles económicos, de formación y de cualificación profesional así como de las condiciones de vida.La etnicización del vinculo (lazo) social, se ha acentuado con las políticas públicas inspiradas por un enfoque de diferencia étnica difícilmente justificable desde la prisma del principio de igualdad

\footnotetext{
${ }^{12} \mathrm{Se}$ trata de un nuevo concepto extraído del contexto americano, que dentro del marco de la polítique de la ville, pretende reforzar las capacidades de las poblaciones residentes en los banlieues para participar en la transformación de la ciudad. Rompe con la concepción tradicional de renovación de las infraestructuras urbanas.
} 
republicana, pero que se disfraza bajo el calificativo de "territorial". De esta forma, oficialmente se opta por encarar los problemas de integración socio económica y urbana desde la preferencia por medidas que no vayan dirigidas de forma específica a la población inmigrante (Lochak, 2008).

Desde este punto de vista, no es de extrañar que para atajar la situación de apartheid social y de relegación urbana, el Primer ministro Manuel Valls sigue situándose en la lógica tradicional de la "politique de la ville", optando así por encarar los problemas desde un enfoque territorial y desde la preferencia por medidas que no vayan dirigidas de forma específica a la población inmigrante (Lochak, 2008). En efecto, la "polítique de la ville" desarrolla medidas de lucha contra la exclusión, en un marco territorial, en favor de zonas urbanas donde la precariedad social es fuerte y conducida por el Estado en partenariado contractual con las administraciones locales (Cour des Comptes, 2004). Es así que después de reunir el Comité Interministerial de la "politique de la ville", el Primer ministro anunció el 6 de marzo un programa político, más que mediatizado "para la igualdad y la ciudadanía" dotado de un presupuesto de 1000.000 .000 (mil millones de euros) a favor de los barrios catalogados como Zonas Urbanas Sensibles (ZUS), proponiendo una "estrategia común" para evitar que las familias pobres con derecho oponible al alojamiento (Droit opposable au logement- DALO) sean alojadas en los barrios más pobres y sean repartidas en toda la geografía nacional ${ }^{14}$.

Esta dificultad política de encarar los problemas socioeconómicos de los inmigrantes y corregir las desigualdades que padecen desde un enfoque de discriminación por motivos de origen étnico o racial denota de la argucia de la asimilación. En efecto, desde el punto de vista factual y empírica, la asimilación implica un proceso de convergencia y igualación (o por lo menos aproximación) estructural hacia los estándares socioecomicos del mainstream society. Proyecta la promesa de trato igual y no discriminación en aras a construir conjuntamente una sociedad inclusiva y cohesionada. En esto consiste su proyecto de homogenización social y estructural, siendo considerado el mainstream como clase social uniforme, en términos de integración residencial, económica, educativa y todo aquello relacionado con la estratificación y movilidad social (Duncan y Duncan, 1968).

\subsection{Un subproceso cultural: La "inseguridad cultural"}

El multiculturalismoa la francesa se evidencia por el desarrollo de un subproceso cultural de pérdida progresiva no solo de las coordenadas sino también del estatus de referente cultural (cultural mainstream) de la propia sociedad receptora de la inmigración. El filósofo francés Alain Finkielkraut (2013), achaca esta pérdida por la invasión y el poder totalizadorde las oleadas de la inmigración laboral y de reagrupamiento familiar de la posguerra:

\footnotetext{
${ }^{13}$ Zappi, S: "Le plan du gouvernement contre l'apartheid, sans mesures chocs ni gros moyens, Le Monde, 06.03.2015.

${ }^{14}$ El programa incluye otras medidas: servicio cívico, afirmación del principio de laicidad en los servicios público, refuerzo de la lengua francesa en los ciclos de infantil y primaria de la enseñanza, diversificación del acceso a la función pública, creación de la marca "grandes école du numérique", creación de la Agencia de desarrollo económico de territorios y mejora del dispositivo de Zona de Seguridad Prioritaria (ZSP)
} 
"Avec le passage d'une immigration de travail à une immigration familiale, les autochtones ont perdu le statut de référent culturel qui était le leur dans les périodes précédentes de l'immigration. Ils ne sont plus prescripteurs. Quand le cybercafé s'appelle Bled.com et que la boucherie ou le fast-food ou les deux sont halal, ces sédentaires font l'expérience déroutante de l'exil. Quand ils voient se multiplier les conversions à l'islam, ils se demandent où ils habitent. Ils n'ont pas bougé, mais tout a changé autour d'eux. Ont-ils peur de l'étranger? Se ferment-ils à l'Autre? Non, ils se sentent devenir étrangers sur leur propre sol. Ils incarnaient la norme, ils se retrouvent à la marge (...) Plus l'immigration augmente, et plus le territoire se fragmente."

El discurso de Finkielkraut concuerda con las conclusiones de Laurent Bouvet (2015), plasmadas en su reciente libro titulado: "l'insécurité culturelle. Sortir du malaise identitaire francais". Según Guilly (2004), la inseguridad cultural es un resentir de las categorías populares confrontadas a la intensificación de los flujos migratorios en el contexto de una sociedad multicultural. Se trata de una ansiedad por la pérdida de un estatus cultural experimentada por las clases populares franceses, un resentir que expresa una nueva forma de inseguridad, que no es ni físico, ni social ni económico, más bien cultural, por el paso de un estatus de "referente cultural" mayoritario al de una minoría dentro del barrio.

El enfoque de la "inseguridad cultural" se nutre, obviamente, de la percepción del islam (como religión y como cultura) como marcador identitario. En efecto, el gran debate que surgió del affaire du foulard tuvo el mérito de poner en la palestra pública una polémica con profundas implicaciones políticas, sociales y religiosas en torno a las interacciones del trinomio Islam, laicidad y República. Hasta entonces, la sociedad francesa no había debatido a fondo sobre dos cuestiones fundamentales: el lugar que en la República ocupa el Islam, que ha llegado a ser la segunda religión en Francia, así como sus implicaciones en el principio de laicidad y los riesgos de comunitarismo y fundamentalismo; y la cuestión relativa a la religión y el principio de igualdad de género. Todo este debate se desarrolló en el contexto del auge electoral de la extrema derecha de Jean-Marie Le Pen en las legislativas parciales de Dreux, con un 42\% de los votos, y de Marsella, con un 33\% de los votos (Gaspard y Khosrokhavar, 1995), y con el telón de fondo del temor al fundamentalismo islámico y al antisemitismo.

Hoy en día el debate sobre el islam oscila entre la asimilabilidad del islam a las democracias occidentales y la incompatibilidad de su "poder tolalizador" (Lewis, 1998 y Huttington, 1997) con los principios de laicismo, de democracia y de libertad, propios de la civilización occidental. Aunque son muy loables los replanteamientos de la identidad musulmana en el suelo europeo a través de una nueva formación del islam que Bassam Tibi (2002) llama "Euro-islam", o sea, "una variedad liberal del que resulte tan aceptable para los inmigrantes musulmanes como para las sociedades europeas, por el hecho de adaptarse a las ideas de laicismo y de ciudadanía individual propias de la democracia moderna", lo cierto es los datos empíricos demuestran que en el contexto francés, el islam es un marcador identitario, que pone en jaque la cohesión de la sociedad francesa. 


\subsection{Un subproceso demográfico: El dinamismo demográfico de los inmigrantes musulmanes y la capacidad expansiva de su religiosidad.}

Aunque las estadísticas religiosas están prohibidas en Francia (la ley de 6 de enero de 1978), el número exacto de musulmanes no ha sido objeto de un censo preciso. Pero las encuestas de opinión que preguntan directamente sobre la pertenencia religiosa pueden ser realizadas. Sobre esta ultima base, el Pew Research Center avanzaba en enero de 2011 la cifra de 4,7 millones de musulmanes en Francia ${ }^{15}$, de los cuales 4 millones son Magrebíes (Bassam Tibi, 2002:63). Tribalat (2013) considera que estos datos demuestran por una parte que Francia es el país de la UE-27 que alberga más inmigrantes musulmanes en número y en proporción y por otra parte esta comunidad musulmana es esencialmente producto de la inmigración de la segunda mitad del siglo XX y del siglo XXI. Partiendo de las estadísticas que presenta en su libro "Assimilation. Fin du modèle français" (2013) Michèle Tribalat afirma que la comunidad musulamana de Francia es cada vez más practicante y cada vez menos personas de religión musulmana abandonan su fe, cada vez más que los catolicos, los musulmanes ponen, según estos sondeos, más importancia a la religión o sea su apego a la religión.

Para esta autora, esta situación contrasta con la situación que prevalecía en lo años 60 en los que la preocupación mayor era llegar a ser ciudadano francés y se menospreciaba el hecho religioso, siendo alentado el fundirse en el créuset francais. Entonces la asimilación funcionaba.En los ultimos años, con la perdida de lamezcolanza geografica y matrimonial, vectores de la secularización, cada vez más la religión ocupa el primer lugar en la educación de los hijos. La generalización de la endogamia se convierte también en un medio para asegurar la transmisión y la fidelidad a la religión.

Ahora bien, la previsión de crecimiento demografico de la población musulmana en Francia apunta hacia una aceleración en los años venideros. Michèle Tribalat fundamenta esta previsión sobre la base de 4 factores: una fuerte fecundidad de la jovenes musulmanas, una endogamia estricta, la fuerte cultura de transmisión de la religión, y la previsón de los importantes flujos migratorios que vendrán a Europa.El dinamismo demografico se apoya sobre los siguientes datos: en el año 2008, Francia registraba el nacimiento de 115.000 niños potencialmente musulmanes, algo más que el 145 de nacimiento en el todo el conjunto de Francia. Así concluye Tribalat (2013 :180):

«Le taux d'accroissement des musulmans est donc incomparablement supérieur à celui des non-musulmans, pour lesquels le solde migratoire est relativement neutre et le taux d'accroissement naturel huit fois inférieur à celui des musulmans. En 2008, l'accroissement démographique des musulmans fait presque jeu égal avec celui des non musulmans et le taux de croissance de la population musulmane a été 12 fois supérieur à celui du reste de la population".

\footnotetext{
${ }^{15}$ http://www.lexpress.fr/actualite/societe/religion/les-francais-surestiment-largement-le-nombrede-musulmans-dans-le-pays_1617055.html http://www.theguardian.com/news/datablog/2014/oct/29/todays-key-fact-you-are-probablywrong-about-almost-everything

Tribalat proporciona la cifra de 4,2 millones.
} 
La tasa de fecundidad de la mujeres musulmanas es superior a la media: 2,8 hijos/por mujer para la generación de 1958-1968 mientras que la media era entonces de 1,9 y 2,3 hijos por mujer en la generación de 1958-1973 mientras que la media era de 1,7 hijos/por mujer.

\section{Conclusión}

Partiendo del presupuesto de fracaso de 30 años de la integración republicano, algunas voces críticas han apelado al reconocimiento explícito del comunitarismo en Francia (Wieviorka, 1996), cierto es que el principio de igualdad cívica y de ciudadanía individual nunca ha sido cuestionado al ser considerado como un principio moral, político y social fundador de la "República". Hoy por hoy, el verdadero debate en torno al principio de igualdad cívica y de ciudadanía individual, tal y como lo afirma Schnapper (1998), consiste en considerar "hasta qué punto las identidades, las referencias culturales así como las fidelidades particulares pueden o deben ser reconocidos en la vida pública".

Sin embargo, hemos de reconocer que tanto en el discurso político sobre la inmigración como en la tradición sociológica francesa existe una casi unanimidad sobre la necesidad de no trasponer al contexto francés los elementos configuradores del modelo anglosajón (Favell, 2001, Schnapper, 1998). El principio de igualdad cívica y de ciudadanía individual, anclado históricamente en "la tradición de integración nacional que no reconoce las comunidades particulares en el espacio público" (Schnapper, Ibis), es también una convicción en los trabajos desarrollados por la sociología francesa de la modernidad, iniciada por Emile Durkheim (1893), que previó el debilitamiento de los vínculos étnicos en la vida colectiva. En efecto, desde los presupuestos de Durkheim, la modernidad es concebida como una evolución política y social que supone despojar al individuo de sus ataduras heredadas. El paso a la sociedad moderna es un proceso de emancipación de las solidaridades particulares por parte de los individuos. Y en este sentido el estatuto de ciudadano representa esta liberación del individuo de todas las ataduras colectivas, salvo del vínculo con el Estado. El individuo ya no está socializado por sus lazos étnicos, considerados como primarios, sino por su lugar en una sociedad más amplia. Es el paso de la "solidaridad mecánica" a la "solidaridad orgánica" (Durkheim ,1893).

El proceso de etnicización de las relaciones sociales, que ha generado un apartheid social, territorial y étnico ha conformado un modelo propio, aunque sin respaldo normativo, de multuculturalismo a la francesa. Uno de las características principal de este modelo, no es el comunitarismo sino un modo funcionamiento comunitario de la sociedad, que sitúa la comunidad "étnica" como centro aglutinador de la vida social, creadora y administradora de recursos propios, que proporciona seguridad a sus miembros, al margen de su no reconocimiento jurídico y político de estamento intermediario entre el estado y sus ciudadano. 


\section{BIBLIOGRAFIA}

- (2001) BARRY, Brian, Culture and equality: An egalitarian critique of multiculturalism. Harvard University Press, Cambridge, MA

- (2008) BEAUJEAU, Mélodie "Le modèle français d'intégrationdans tous ses états: Entre reaffirmationsrépublicaines et tentations populistes", International Journal on Multicultural Societies (IJMS), UNESCO, Vol. 10, No 1.

- (1993) BLANCO VALDERRAMA, María Cristina, La integración de los inmigrantes en las sociedades receptoras. Métodos de análisis y aplicación al País Vasco, Tesis. Universidad de Deusto.

- (2015) BOUVET, Laurent, 2015, L'insécurité culturelle. Le malaise identitaire français, Fayard. Paris

- (1992) BRUBAKER, Roger, Citizenship and Nationhood inFranceand Germany, Harvard UniversityPress, Cambridge, MA

- (2010) CACHÓN, Lorenzo, Informe sobre la situación de la integración social de inmigrantes y refugiados en España 2009, Ministerio de Trabajo e Inmigración, Madrid

- (2009) CALDERON VÁZQUEZ, Francisco- José. "El multiculturalismo revisitado", Revista de Relaciones internacionales y ciencias políticas http://www.eumed.net/rev/sg/03/fjcv.htm

- (1992) CASTLES Stephen, "The Australian model of immigration and multiculuralism: Is it applicable to Europe? ", International Migration Review, 26(2), pp. 549-567.

- (1991) COSTA- LASCOUX, Jacqueline, Réussir l'intégration: assimiler, insérer, intégrer, Projet, Paris.

- $\quad(1992)$

"L'immigration au gré des politiques". En Férréol, Gilles (Ed.), Intégration et exclusion dans la société française contemporaine, Presses Universitaires de Lille, Lille.

- (1991) De l'immigré au citoyen, La documentation française, Paris. 
- $\quad$ (2005) "L'ethnicisation du lien social dans les banlieues françaises", Revue Européenne des Migrations Internationales, 17(2), pp. 123138.

- (2006) "L'intégration "à la française": une philosophie à l'épreuve des réalités", Revue européenne des migrations internationales, vol. 22, 2,

- (2004) COUR DES COMPTES, L'accueil des migrants et l'intégration des populations issues de l'immigration. Rapport au Président de la République, Cour des Comptes, Paris.

- (1968) DUNCAN Beverly y DUNCAN Otis Dudley."Minorities and the process of stratification" American Sociological Review, Vol. 33, No. 3 pp. 356364 http://www.jstor.org/stable/2091911 .

- (1893) DURKHEIM,De la division du travail social, Alcan, Paris. Cinquième édition

- (2001) FAVELL, Adrian "Integration policy and integration research in Europe: a review and critique" Citizenship today: global perspectives and practices, 2001, vol. 349, p. 351-52.

- (1998)

Philosophies of integration: immigration and the idea of citizenship in France and Britain. Macmillan/Centre for Research in Ethnic Relations, Basingstoke.

- $\quad$ (2013) FINKIELKRAUT, Alain, L'identité malheureuse, Stock, Paris

- (2015) GIESEN, Klaus-Gerd, L'insécurité culturelle: usages et ambivalences. Notes critiques à propos du livre de Laurent Bouvet.L'Espace Politique. Revue en ligne de géographie politique et de géopolitique.

http://espacepolitique.revues.org/3326

- (2014) GUILLUY, Christophe, La France périphérique. Comment on a sacrifié les classes populaires, Flammarion, Paris.

- $\quad$ (1993) HAUT CONSEIL A L'INTÉGRATION, L'Intégration à la française. La Documentation française, Paris.

- $\quad$ (1999)

Lutte contre les discriminations: faire respecter le principe d'égalité. Rapport, La Documentation française, Paris.

- $\quad$ (2001) Les parcours de l'intégration, Rapport au Premier ministre, Collection des rapports officiels, La Documentation française, Paris.

- (2004) Le Contrat et l'intégration, La Documentation française, Paris.

- (2006) Le bilan de la politique d'intégration 20022005, Rapport au Premier ministre, Collection des rapports officiels, La Documentation française, Paris.

- (1998)

Documentation française, Paris.

Rapport relatif aux discriminations, La

- (2001)

Quelle efficacité pour les politiques d'intégration ? Cinquante ans de politiques publiques d'intégration, Cahiers français $n^{0}$ 352. http://www.hci.gouv.fr/IMG/pdf/Cahiers_Francais_integration2.pdf

- (2002) HERAN, Francçois "Les immigrés et leurs descendants dans le système statistique français: réflexions sur les pratiques et les principles". En 
Immigration, marchédu travail et intégration, Rapport du séminaire présidé par F. Héran, La documentation française, pp. 120-133.

- (2004) Cinq idées recues sur l'immigration, Populations et sociétés, INED.

- (1997) HUNTINGTON Samuel, The Clash of Civilizationsand the Remaking of World Order, Simon \& Schuster, New York.

- (2003) JOPPKE Christian y MORAWSKA, Eva (Eds) (2003): Toward Assimilation and Citizenship: Immigrants in Liberal Nation-States, PalgraveMacmillan, London.

- (2010) JOPPKE Christian, Citizenship and Immigration, Polity Press, Cambridge.

- $\quad$ (2014) ."Europe and Islam: Alarmists, Victimists, and Integration by Law", West European Politics 37(6), pp. 1314-1335.

- (2014)_. "The Retreat is Real- But What is the Alternative? Multiculturalism, Muscular Liberalism, and Islam", Constellations 21(2), pp. 286295.

- (2010) . "Minority Rights for Immigrants? Multiculturalism versus Antidiscrimination", Israel Law Review 43, pp. 49-66.

- (2013) KOKOREFF, Michel., LAPEYRONNIE, Didier, Refaire la cité: L'avenir des banlieues, Seuil, La République des idées, Paris.

- (2010) KOUKOUTSAKI- MONIER, Angeliki. (2010): "La construction symbolique de l'identité nationale française dans les discours de la campagne présidentielle de Nicolas Sarkozy", Communication, Vol. 28/1|2010,pp. 11-39. http://communication.revues.org/2010

- (2010) LAGRANGE, Hugues, Le Déni des cultures, Seuil, Paris

en Ile-de-France, Seuil, Paris.

- $\quad$ (1998) LEWIS, Bernard, The Political Language of Islam, The University of Chicago, Chicago.

- (2007) LOCERIE, Françoise, "integration, ethnicisation", Ecarts d'identités, no 111, décembre, pp. 49-51

- (2004) PARSANOGLOU, Dimitris "Multiculturalisme(S)",Socioanthropologie[En ligne], 15 | 2004, mis en ligne le 15 juillet 2006, consulté le 18 avril 2015. URL : http://socio-anthropologie.revues.org/416

- $\quad$ (2007) PIOLAT, Michel Piolat, “ L'ethnicisation/racialisation des rapports interpersonnels", Faire Savoirs, n6, Mai 2007

- (2011) ROJAS MULLOR, Mauricio, Pobreza y exclusión social. La experiencia de la Unión Europea: Conceptos y herramientas de acción. Cuadernos de la EPIC, no 5 Madrid

- (2007) SAFI, Mirna, Le devenir des immigrés en France. Barrières et inegalites. Ecole des Hautes Etudes en Sciences Sociales (EHESS).

- $\quad$ (1992) SCHNAPPER, Dominique, L'Europe des immigrés. Essai sur les politiques d'immigration, François Bourin, Paris.

- (1998) sociologique, Gallimard, Paris.

- (2007) Qu'est ce que l'intégration?, Gallimard, Paris.

- $\quad$ (1991) La France de l'intégration. Sociologie de la nation,

Gallimard, Paris. 
nation, Gallimard, Paris.

- (2003) SIMON, Patrick, "Challenging the "French model of integration": discrimination and the labor market case in France",Studi Emigrazione, 152, p.717-745

- (2001) SMITH Anthony, "Ethno-Symbolism" en. Leoussi, S: (ed.), Encyclopedia of Nationalism, New Brunswick / London, Transaction Publishers, pp. 84-87.

- (2002) TIBI, Bassam: "Los inmigrantes musulmanes en Europa: Entre el euro-islam y el gueto, en Alsyyad, Nezar y Castells, Manuel (Eds): ¿Europa musulmana o euroislam? Política, cultura y ciudadanía en la era de la globalización, Alianza, Madrid

- (2013) TRIBALAT, Michèle, Assimilation. La fin du modèle français, Le Toucan, Paris

- (2012) TSHITSHI NDOUBA, Kayamba, Migraciones y convivencia urbana. Un estudio comparativo sobre los conflictos sociales y la segregación residencial en 6 ciudades europeas, Cuadernos de la EPIC, n' 8 , EPIC, Madrid. - (2013) TUOT, Thierry, La grande Nation: pour une société inclusive Rapport au Premier ministre sur la refondation des politiques d'intégration, la Documentation Française. Paris.

- $\quad$ (1997) WEIL, Patrick, Mission d'étude des législations de la nationalité et de l'immigration: rapports au Premier ministre. La Documentation française, (Collection des rapports officiels), Paris.

- (2005) Immigration, intégration, discriminations, Seuil, Paris.

- (2004) Qu'est-ce qu'un Français? , Paris, Gallimard.

- (2006) La République et sa diversité. Immigration, intégration, discriminations. Seuil: La République des idées, Paris.

- (1993) WEBER, Max, Economía y Sociedad, Fondo de Cultura Económica de España

- (1996) WIEVIORKA, Michel, "Racisme, racialisation et ethnicisation en France" Hommes et Migrations, no 1195, février 1996 pp. 